\title{
Retraction Note to: Diagnostic investigations of canine prostatitis incidence together with benign prostate hyperplasia, prostate malignancies, and biochemical recurrence in high-risk prostate cancer as a model for human study
}

\author{
Radmehr Shafiee $^{1}$ - Alireza Shariat ${ }^{2} \cdot$ Soheil Khalili $^{2} \cdot$ Hamed Zamankhan Malayeri $^{3}$. \\ Aram Mokarizadeh $^{4}$ - Ali Anissian ${ }^{5}$ Mohammad Reza Hafezi Ahmadi ${ }^{6}$. \\ Ehsan Hosseini $^{7} \cdot$ Mostafa Naderafif $^{8} \cdot$ Siamak Mohsenzadeh $^{8}$. \\ Mohammad Hosein Rasoulian ${ }^{9} \cdot$ Reza Rezapour $^{9} \cdot$ Maryam Pourzaer $^{10}$
}

Published online: 8 November 2016

(C) International Society of Oncology and BioMarkers (ISOBM) 2016

Retraction Note to: Tumor Biol (2015) 36:2437-2445

DOI 10.1007/s13277-014-2854-4

This article has been retracted at the request of the Editor-inChief, the International Society of Oncology and BioMarkers (ISOBM) and the Publisher per the Committee on Publication Ethics guidelines. The article shows evidence of irregularities in authorship during the submission process, there is strong reason to believe that the peer review process was compromised and the article contains patchwork plagiarism from a variety of sources.

The main sources are (amongst others):

Bruce E. LeRoya, icole Northrup, Prostate cancer in dogs: Comparative and clinical aspects. The Veterinary Journal. 2009; 180:2 149-162 DOI: 10.1016/j.tvj1.2008.07.012

The online version of the original article can be found at http://dx.doi.org/ 10.1007/s13277-014-2854-4.

Ali Anissian

aanissian@gmail.com

Mohammad Reza Hafezi Ahmadi

Hafezi-m@medilam.ac.ir

Faculty of Veterinary Medicine, Tehran University, Tehran, Iran

2 Faculty of Veterinary Medicine, Karaj Branch, Islamic Azad University, Karaj, Iran

3 Department of Internal Medicine, Faculty of Veterinary Medicine, Tehran University, Tehran, Iran

4 Department of Immunology, Faculty of Medicine, Kurdistan University of Medical Sciences, Sanandaj, Iran
J. Smith, Canine prostatic disease: A review of anatomy, pathology, diagnosis, and treatment, Proceedings of the Annual Conference of the Society for Theriogenology. The Society for Theriogenology 2008 Annual Conference, Theriogenology. 2008; 70:3 375-383 DOI: 10.1016/ j.theriogenology.2008.04.039

H.F. L'Eplattenier, B. Klem, E. Teske, F.J. van Sluijs, S. A. van Nimwegen, J. Kirpensteijn, Preliminary results of intraoperative photodynamic therapy with 5 -aminolevulinic acid in dogs with prostate carcinoma. The Veterinary Journal. 2008; 178:202-207

As such the validity of the content of this article cannot be verified.

Department of Veterinary, College of Agriculture, Abhar Branch, Islamic Azad University, Abhar, Iran

6 Department of Pathology, Faculty of Medicine, Ilam University of Medical Sciences, Ilam, Iran

7 Faculty of Para Veterinary Medicine, Ilam University, Ilam, Iran

8 Department of Pathobiology, Faculty of Veterinary Medicine, Ferdowsi University of Mashhad, Mashhad, Iran

9 Faculty of Veterinary Medicine, Urmia University, Urmia, Iran

10 Department of Biology, Faculty of Basic Science, Damghan Branch, Islamic Azad University, Damghan, Iran 